\title{
Characterizing the molecular epidemiology of Staphylococcus aureus across and within fitness facility types
}

\author{
Mark Dalman ${ }^{1 *}$ D, Sabana Bhatta ${ }^{2}$, Nagashreyaa Nagajothi', Dipendra Thapaliya ${ }^{2}$, Hailee Olson²,
} Haji Mohammad Naimi ${ }^{3}$ and Tara C. Smith ${ }^{2}$

\begin{abstract}
Background: Staphylococcus aureus is a common bacterium found in the nose and throat of healthy individuals, and presents risk factors for infection and death. We investigated environmental contamination of fitness facilities with $S$. aureus in order to determine molecular types and antibiotic susceptibility profiles of contaminates that may be transmitted to facility patrons.

Methods: Environmental swabs $(n=288)$ were obtained from several fitness facilities $(n=16)$ across Northeast Ohio including cross-fit type facilities $(n=4)$, traditional iron gyms $(n=4)$, community center-based facilities $(n=5)$, and hospital-associated facilities $(n=3)$. Samples were taken from 18 different surfaces at each facility and were processed within $24 \mathrm{~h}$ using typical bacteriological methods. Positive isolates were subjected to antibiotic susceptibility testing and molecular characterization (PVL and mecA PCR, and spa typing).

Results: The overall prevalence of S. aureus on environmental surfaces in the fitness facilities was 38.2\% (110/288). The most commonly colonized surfaces were the weight ball (62.5\%), cable driven curl bar, and CrossFit box (62. $5 \%)$, as well as the weight plates (56.3\%) and treadmill handle (50\%). Interestingly, the bathroom levers and door handles were the least contaminated surfaces in both male and female restroom facilities (18.8\%). Community gyms (40.0\%) had the highest contamination prevalence among sampled surfaces with CrossFit (38.9\%), traditional gyms (38.9\%), and hospital associated (33.3\%) contaminated less frequently, though the differences were not significant $(p=0.875)$. The top spa types found overall were t008 $(12.7 \%)$, t267 (10.0\%), t160, t282, t338 (all at 5.5\%), t012 and t442 (4.5\%), and t002 (3.6\%). t008 and t002 was found in all fitness facility types accept Crossfit, with t267 (25\%), t548, t377, t189 (all 10.7\%) the top spa types found within crossfit. All samples were resistant to benzylpenicillin, with community centers having significantly more strains resistant to oxacillin (52.8\%), erythromycin (47\%), clindamycin (36\%), and ciprofloxacin (19\%). Overall, 36.3\% of isolates were multidrug resistant.

Conclusions: Our pilot study indicates that all facility types were contaminated by S. aureus and MRSA, and that additional studies are needed to characterize the microbiome structure of surfaces at different fitness facility types and the patrons at these facilities.
\end{abstract}

Keywords: Athletic fitness facilities, S. aureus, MRSA, Multi-drug resistant, Northeast Ohio, CrossFit, Gym

\footnotetext{
* Correspondence: mdalman@kent.edu

${ }^{1}$ Kent State University, College of Podiatric Medicine, 6000 Rockside Woods

Blvd. N, Independence, $\mathrm{OH}$ 44131, USA

Full list of author information is available at the end of the article
}

(c) The Author(s). 2019 Open Access This article is distributed under the terms of the Creative Commons Attribution 4.0 International License (http://creativecommons.org/licenses/by/4.0/), which permits unrestricted use, distribution, and reproduction in any medium, provided you give appropriate credit to the original author(s) and the source, provide a link to the Creative Commons license, and indicate if changes were made. The Creative Commons Public Domain Dedication waiver (http://creativecommons.org/publicdomain/zero/1.0/) applies to the data made available in this article, unless otherwise stated. 


\section{Background}

Staphylococcus aureus is an opportunistic pathogen that colonizes asymptomatically the skin and nares of approximately 1 in 3 people worldwide [1, 2]. S. aureus is found in hospital settings, and with the emergence of antibiotic resistance, can cause life threatening infections. Recent studies have suggested that, in the United States, over 80,000 invasive infections and 11,000 yearly deaths are attributed to methicillin-resistant $S$. aureus (MRSA) [3]. While the number of invasive MRSA infections has declined slowly over the past decade, our group has identified reservoirs of MSSA (methicillinsusceptible $S$. aureus) and MRSA in humans, animals, and the environment [4-11]. Although colonization with S. aureus is usually asymptomatic, it is a risk factor for active infection [12] and enhances the ability of an individual to transmit $S$. aureus to fomite surfaces [13].

One location that has been associated with an increased risk of both infection and colonization with $S$. aureus is the athletic fitness facility $[14,15]$. Over 50 million individuals in the United States support approximately 30,000 fitness facilities, and the number continues to rise [14]. MRSA infections have been linked to contamination of athletic facilities due to shared exercise equipment [15] and towels [16]. Facility-associated MRSA infections have also been documented in both professional and collegiate athletic teams [17-19], and even in high school athletes $[20,21]$. The link between fitness facilities and contaminated surfaces is unclear [22], but Markley and colleagues [15] found that approximately $10 \%$ of gym surfaces were contaminated with $S$. aureus and these contaminated fomites may serve to spread $S$. aureus. However, not all fitness facility types and surfaces may warrant the same scrutiny.

In the present study, we assessed the prevalence of $S$. aureus and MRSA across several fitness facility types to characterize the microbial environment and potential for $S$. aureus transmission, to identify potential risks associated with certain areas, environmental conditions, or types of exercise equipment, and to provide a more inclusive study addressing exercise facility type as a facilitator of $S$. aureus transmission.

\section{Methods}

\section{Facility sampling}

We performed point prevalence microbiological surveys at 16 fitness facilities in Northeast Ohio. The facilities were convenience-sampled with the surfaces selected as the most commonly hand-touched areas in the building. Environmental swabs were obtained from CrossFit type facilities $(n=4)$, traditional free weight gyms $(n=4)$, community center facilities $(n=5)$, and hospital -associated facilities $(n=3)$ with the written permission of the owners. Traditional free weight gyms only have weights for lifting and do not offer any other services such as a pool or daycare. Community center facilities were usually larger facilities with a wide range of services from yoga, gyms for basketball or volleyball, swimming pools, daycare services, rock climbing walls, and food preparation. Hospital-associated facilities were linked to a hospital or clinic and had weights, swimming pool, and guided care for rehabilitation purposes, in addition to providing membership access to the general public. CrossFit facilities involved highly intensive, varied movement exercises covering several sports movements, and were required to self-identify as a CrossFit facility for inclusion purposes.

The sampling technique of surfaces was as previously described [7]. Briefly, a sterile Swiffer ${ }^{\circ}$ cloth was used to wipe down a 9 square inch environmental surface for 10 $\mathrm{s}$ using a new set of gloves for each surface as to reduce cross contamination. Samples were then placed in a labeled, individual sterile Whirl-Pak ${ }^{\mathrm{Tm}}$ bag (Nasco, Fort Atkinson, WI) and stored on ice until returning to the lab for processing within $3 \mathrm{~h}$ of acquisition.

\section{Bacterial culture and identification}

Samples were processed as previously described [23]. Samples were reconstituted in $50 \mathrm{~mL}$ of sterile $0.1 \%$ peptone broth and massaged for $25 \mathrm{~s}$ to enhance bacterial recovery. Subsequently, this peptone solution was transferred to a $50 \mathrm{~mL}$ aliquot of sterile, 2X Baird Parker Broth (BPB) solution with tellurite enrichment (Sigma products-Sigma Aldrich, St. Louis, MO) and allowed to incubate at $37^{\circ} \mathrm{C}$ for $24 \mathrm{~h}$. After incubation, $1 \mu \mathrm{L}$ inoculums were streaked onto Baird Parker Agar (BPA) with EY tellurite enrichment and selective MRSA agar plates (BBL CHROMagar MRSA, Becton, Dickinson and Company), and allowed to incubate for $48 \mathrm{~h}$ at $37^{\circ} \mathrm{C}$. Potential S. aureus colonies (black colonies) and presumptive MRSA colonies (mauve colonies on CHROMagar) were then plated on Columbia colistin- nalidixic acid agar with 5\% sheep's blood (CNA; Ramel). Plated CNA were allowed to grow at $37^{\circ} \mathrm{C}$ for $24 \mathrm{~h}$. Colonies were confirmed using a series of biochemical assays including: catalase, coagulase, and $S$. aureus latex agglutination (Pastorex Staph-Plus, Bio-Rad, Hercules, CA). Confirmed $S$. aureus isolates were stored at $-80^{\circ} \mathrm{C}$ with a single colony used for antibiotic susceptibility testing (AST) and subsequent molecular analyses.

\section{Molecular characterization}

Positive S. aureus isolate genomic DNA was isolated using Wizard Genomic DNA preparation kit (Promega, Madison, WI). Polymerase chain reaction (PCR) was used to amplify the presence of methicillin resistance gene $(m e c \mathrm{~A})$ and PVL genes $(l u k \mathrm{~S}, l u k \mathrm{~F})[24,25]$. Furthermore, Staphylococcus protein A (spa; FOR 5'-GAAC 
AA-CGTAACGGCTTCATCC-3' and REV 5'-CAGC AGTAGTGCCGTTTGCCT) was used for molecular typing [26-28]. Ridom StaphType software was used to assign spa types (v2.2.1; Ridom GmbH, Wurzburg, Germany). The Based upon Repeat Pattern (BURP) algorithm was used to group spa types based on their genetic proximity [29], as well as Bionumerics software (version 7.6.2). Only spa typing was conducted, since previous studies have found high congruence and discriminatory power compared to MLST sequence data [28, 30, 31]. A positive (USA300) and negative control were used for all biochemical and molecular assays.

\section{Antimicrobial susceptibility testing (AST)}

All $S$. aureus isolates were subjected to AST by VITEK 2 system (bioMerieux, Durham, NC; Version R06.01) using AST-GP71 cards according to manufacturer's and Clinical Laboratory Standards Institute Standards (CLSI, 2012). A (0.5-0.63 OD) bacterial suspension in $0.45 \%$ saline was prepared for each sample tested. AST-GP71 cards test for: benzylpenicillin, oxacillin, tetracycline, erythromycin, ciprofloxacin, moxifloxacin, minocycline, clindamycin, trimethoprim-sulfamethoxazole, quinupristin/ dalfopristin, gentamicin, levofloxacin, linezolid, daptomycin, vancomycin, rifampin, tigecycline, and nitrofurantoin. Resistance to $\geq 3$ class of antibiotics was considered as multi-drug resistant (MDR) [32].

\section{Environmental factors}

Temperature and relative humidity measurements were collected at all locations at a central point away from any external door or HVAC vent. Temperature and relative humidity measurements were collected at the end of sampling $(\sim 45-60 \mathrm{~min})$ to ensure that the temperature and relative humidity were indicative of the gym facility, and not a carryover from transport or previous location. Total patron membership numbers and cleaning regimens were also collected via a self-reported questionnaire.

\section{Statistical analysis}

Association of variables was tested by Pearson's Chisquare test in addition to Fisher's exact test for outcome. For all analyses, $\mathrm{P}$ was set at 0.05 with all tests carried out using SAS software (Ver. 9.3, SAS Institute Inc., Cary, NC). Minimum spanning tree was conducted using Bionumerics software (7.6.2).

\section{Results}

Prevalence of S. aureus

A total of 288 environmental samples (fitness facility surface samples) were collected from 16 fitness facilities in Northeast Ohio. A total of 110 sites were identified as $S$. aureus-positive. The overall prevalence of $S$. aureus for all locations was $38.2 \%(110 / 288)$ with a prevalence of $26.7 \%(77 / 288 ; \pm 1.65 \%$ SE) and $11.5 \%(33 / 288 ; \pm 3.95 \%$ SE) for MSSA and MRSA respectively (Table 1). There was an average of $27.5 \pm 3.69$ (Mean \pm SE) positive isolates per site type. Table 1 shows the distribution of $S$. aureus across multiple fitness facility types sampled. We found similar S. aureus contamination across fitness facilities buildings (community: 40.0\%, 36/90; traditional: 38.9\%, 28/72; CrossFit: $38.9 \%, 28 / 72$; and hospital-associated: $33.3 \%, 18 / 54)$. The prevalence of MSSA was significantly higher compared to MRSA $(p=0.024)$, while the total number of contaminated surfaces was not significantly different across fitness facility types (Table $1 ; p=0.875$ ). The highest prevalence of $S$. aureus was observed on the weight ball $(62.5 \%, 10 / 16)$ and cable-driven curl bar/ CrossFit box $(62.5 \%, 10 / 16)$, followed by weight plates $(56.3 \%, 9 / 16)$, treadmill handle/free rope $(50.0 \%, 8 / 16)$, and water fountain $(50.0 \%, 8 / 16)$ (Fig. 1). Interestingly, based on mecA presence, MRSA contamination was higher in community-associated fitness facilities (52.8\%, $19 / 36)$ compared to hospital-associated $(5.56 \%, 1 / 18)$, CrossFit $(14.3 \%, 4 / 28)$, and traditional fitness facilities (32.1\%, 9/28) (Table $1 ; p=0.001)$.

MRSA $=$ Methicillin resistant $S$. aureus. MSSA = Methicillin susceptible $S$. aureus.

Table 1 Prevalence of S. aureus (MRSA and MSSA) by fitness facility type

\begin{tabular}{|c|c|c|c|c|c|c|c|c|c|c|c|}
\hline \multicolumn{3}{|c|}{ Traditional } & \multicolumn{3}{|c|}{ Community } & \multicolumn{3}{|c|}{ Hospital } & \multicolumn{3}{|c|}{ Crossfit } \\
\hline \multicolumn{3}{|c|}{$\begin{array}{c}\text { Total positive isolates } n=28 \\
4 \text { Facilities sampled }\end{array}$} & \multicolumn{3}{|c|}{$\begin{array}{c}\text { Total positive isolates } n=36 \\
5 \text { Facilities sampled }\end{array}$} & \multicolumn{3}{|c|}{$\begin{array}{l}\text { Total positive isolates } n=18 \\
3 \text { Facilities sampled }\end{array}$} & \multicolumn{3}{|c|}{$\begin{array}{c}\text { Total positive isolates } n=28 \\
4 \text { Facilities sampled }\end{array}$} \\
\hline Facility & MRSA (n) & $\operatorname{MSSA}(n)$ & Facility & MRSA (n) & $\operatorname{MSSA}(n)$ & Facility & MRSA (n) & $\operatorname{MSSA}(n)$ & Facility & MRSA (n) & $\operatorname{MSSA}(n)$ \\
\hline $\mathrm{A}$ & 0 & 10 & $\mathrm{E}$ & 4 & 6 & $\mathrm{~J}$ & 0 & 7 & $\mathrm{M}$ & 1 & 7 \\
\hline B & 5 & 3 & $\mathrm{~F}$ & 7 & 2 & K & 0 & 6 & $\mathrm{~N}$ & 3 & 4 \\
\hline $\mathrm{C}$ & 1 & 4 & G & 1 & 6 & $\mathrm{~L}$ & 1 & 4 & $\mathrm{O}$ & 0 & 7 \\
\hline \multirow[t]{3}{*}{$\mathrm{D}$} & 3 & 2 & $\mathrm{H}$ & 5 & 0 & & & & $\mathrm{P}$ & 0 & 6 \\
\hline & & & I & 2 & 3 & & & & & & \\
\hline & $9(32.1 \%)$ & $19(67.9 \%)$ & & $19(52.8 \%)$ & $17(41.2 \%)$ & & $1(5.60 \%)$ & $17(94.4 \%)$ & & $4(14.3 \%)$ & $24(85.7 \%)$ \\
\hline
\end{tabular}




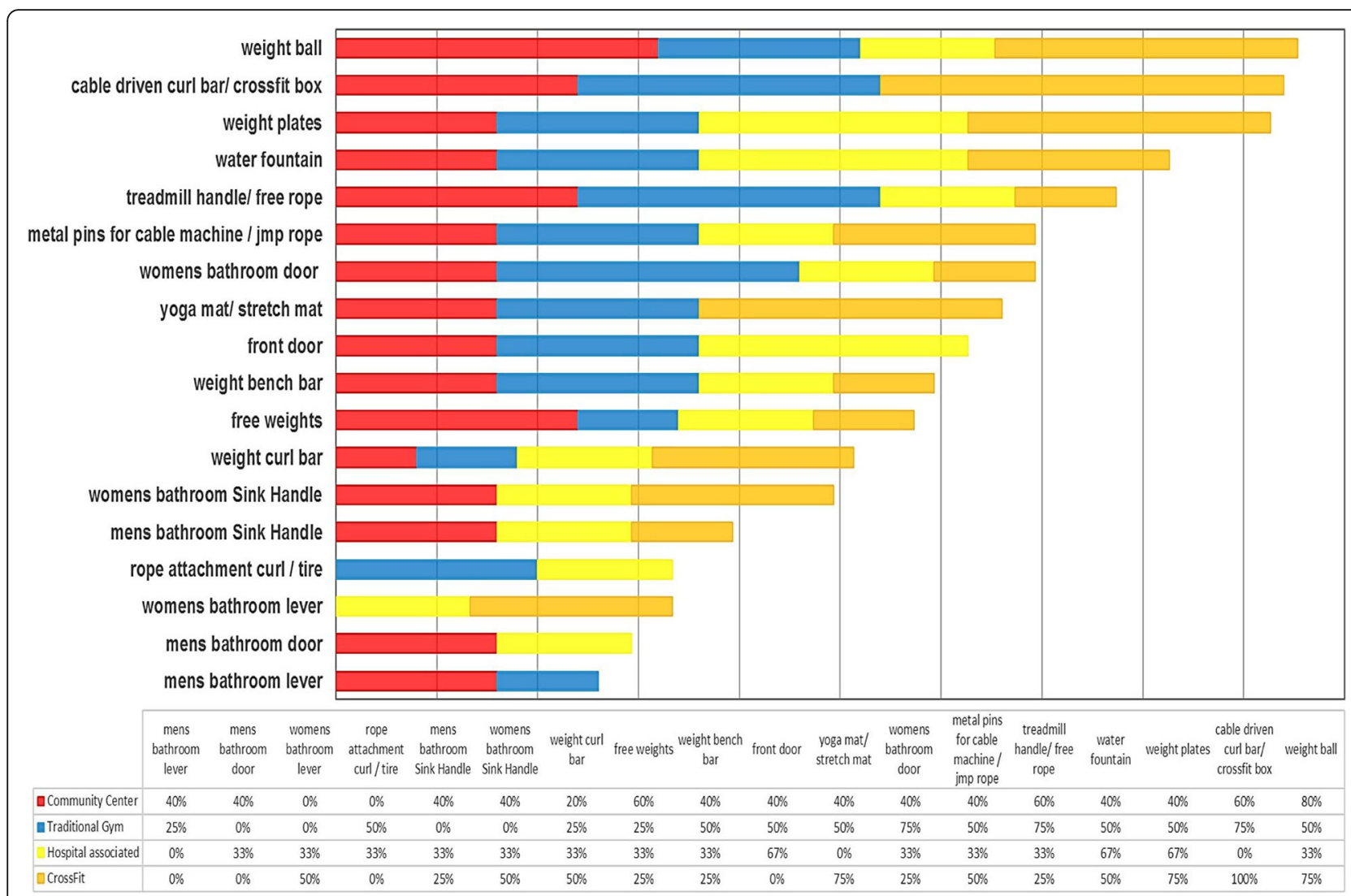

Fig. 1 S. aureus percent contamination for each fitness facility and surface type

Under facility type (Traditional, Community, Hospital, and Crossfit), each facility (A through P) had 18 samples taken and only positive MRSA or MSSA are reported here.

Facilities A through P represent unique facility addresses.

\section{Molecular characterization of $S$. aureus isolates}

Molecular typing of the spa gene was performed on all confirmed $S$. aureus isolates, in addition to examination of presence of the mecA and PVL genes. A total of 38 unique spa types were identified among 110 isolates with the most common 14 spa types present in at least three or more surfaces. The most common spa type present was t008 (12.7\%; 14/110), followed by t267 (10.0\%; $11 /$ 110), t160, t282, t338 (all at 5.45\%; 6/110), t012, t442 (both at 4.55\%; 5/110), t002, t026, t334 (all at 3.64\%; 4/ 110), $\mathrm{t} 148, \mathrm{t} 189, \mathrm{t} 377$, and $\mathrm{t} 548$ (all at $2.73 \% ; 3 / 110$ ) (Table 2; Fig. 2). Of 33 MRSA isolates, 33.3\% were t008. The most common spa types found in each fitness type were t267 (25.0\%; 7/28; CrossFit), t012 (22.2\%; 4/18; hospital- associated), t008 (22.2\%; 8/36; community center), and t008 and t016 were tied for the most common in the traditional free-weight gym $(17.9 \% ; 5 / 28)$.

The prevalence of the mecA gene among $S$. aureus isolates was $30.0 \%(33 / 110)$. MRSA was isolated from
14.3\% (4/28) of isolates in CrossFit facilitates, 5.6\% (1/ 18) of hospital-associated facilities, $52.8 \%$ (19/36) of community facilities, and $32.1 \%$ (9/28) of traditional gym facilities (Table 2). There was a significant difference observed between fitness facility types $(p=0.001)$. There were only three isolates $(2.7 \% ; 3 / 110)$ that were PVL-positive and were correspondingly found only in community facilities.

\section{Antibiotic susceptibility profile}

All $S$. aureus isolates were subjected to antibiotic susceptibility testing. Cumulatively, 37 isolates $(33.6 \%)$ were resistant to erythromycin, 33 (30.0\%) were resistant to oxacillin, $29(26.4 \%)$ were resistant to clindamycin, 9 (8.2\%) were resistant to tetracycline, 11 (10.0\%) were resistant to ciprofloxacin, 11 (10.0\%) were resistant to levofloxacin, and 4 (3.6\%) were resistant to minocycline (Fig. 3). Forty isolates (36.3\%) were MDR- S. aureus. The 4 isolates that demonstrated intermediate resistance to vancomycin were found within community (1), CrossFit (2), and hospital (1) -associated facilities. Community-associated facilities had significantly more oxacillin $(52.8 \% ; 19 / 36 ; p=0.001)$, levofloxacin (22.2\%; 8/36; $p=0.021)$, clindamycin $(36.1 \% ; 13 / 36 ; p=$ $0.025)$, erythromycin $(47.2 \% ; 17 / 36 ; p=0.054)$, and ciprofloxacin $(19.4 \% ; 7 / 36 ; p=0.056)$ resistant strains compared to hospital, crossfit, and traditional facility types. 
Table 2 S. aureus spa typing by fitness facility location

\begin{tabular}{|c|c|c|c|c|c|c|c|c|c|c|c|}
\hline \multicolumn{3}{|c|}{$\begin{array}{c}\text { Crossfit } \\
\text { Gym }\end{array}$} & \multicolumn{3}{|c|}{$\begin{array}{l}\text { Hospital- } \\
\text { Associated }\end{array}$} & \multicolumn{3}{|c|}{$\begin{array}{l}\text { Community } \\
\text { Associated }\end{array}$} & \multicolumn{3}{|c|}{$\begin{array}{c}\text { Traditional } \\
\text { Gym }\end{array}$} \\
\hline$\%$ & $\mathrm{n}$ & type & $\%$ & $\mathrm{n}$ & type & $\%$ & $\mathrm{n}$ & type & $\%$ & $\mathrm{n}$ & type \\
\hline $25 \%$ & 7 & t267 & $22 \%$ & 4 & t012 & $22 \%$ & 8 & t008 & $18 \%$ & 5 & t008 \\
\hline $11 \%$ & 3 & t548 & $11 \%$ & 2 & t002 & $11 \%$ & 4 & t282 & $18 \%$ & 5 & $\mathrm{t} 160$ \\
\hline $11 \%$ & 3 & t377 & $11 \%$ & 2 & t026 & $11 \%$ & 4 & t267 & $11 \%$ & 3 & $\mathrm{t} 442$ \\
\hline $11 \%$ & 3 & t189 & $11 \%$ & 2 & t148 & $6 \%$ & 2 & t338 & $7 \%$ & 2 & t026 \\
\hline $7 \%$ & 2 & t084 & $11 \%$ & 2 & t338 & $6 \%$ & 2 & t442 & $7 \%$ & 2 & t062 \\
\hline $7 \%$ & 2 & t282 & $6 \%$ & 1 & t008 & $6 \%$ & 2 & t922 & $7 \%$ & 2 & $\mathrm{t} 2726$ \\
\hline $7 \%$ & 2 & t334 & $6 \%$ & 1 & t073 & $3 \%$ & 1 & t002 & $4 \%$ & 1 & t002 \\
\hline $7 \%$ & 2 & t4371 & $6 \%$ & 1 & $\mathrm{t} 160$ & $3 \%$ & 1 & t012 & $4 \%$ & 1 & t003 \\
\hline $4 \%$ & 1 & t338 & $6 \%$ & 1 & t216 & $3 \%$ & 1 & t051 & $4 \%$ & 1 & t164 \\
\hline $4 \%$ & 1 & t346 & $6 \%$ & 1 & t334 & $3 \%$ & 1 & t1154 & $4 \%$ & 1 & t179 \\
\hline $4 \%$ & 1 & t360 & $6 \%$ & 1 & t688 & $3 \%$ & 1 & t148 & $4 \%$ & 1 & t1954 \\
\hline $4 \%$ & 1 & t688 & \multirow{9}{*}{\multicolumn{3}{|c|}{18}} & $3 \%$ & 1 & t179 & $4 \%$ & 1 & t216 \\
\hline & 28 & & & & & $3 \%$ & 1 & $\mathrm{t} 2414$ & $4 \%$ & 1 & t276 \\
\hline & & & & & & $3 \%$ & 1 & t242 & $4 \%$ & 1 & t334 \\
\hline & & & & & & $3 \%$ & 1 & t334 & $4 \%$ & 1 & t346 \\
\hline & & & & & & $3 \%$ & 1 & t345 & \multirow{5}{*}{\multicolumn{3}{|c|}{28}} \\
\hline & & & & & & $3 \%$ & 1 & t7540 & & & \\
\hline & & & & & & $3 \%$ & 1 & $\mathrm{t} 774$ & & & \\
\hline & & & & & & $3 \%$ & 1 & t7954 & & & \\
\hline & & & & & & $3 \%$ & 1 & t8504 & & & \\
\hline
\end{tabular}

\section{Environmental factors}

Temperature and relative humidity measurements were collected at all locations, as were patron membership numbers. The mean facility temperature across all facilities was $21.5^{\circ} \mathrm{C}\left(70.7^{\circ} \mathrm{F} \pm 2.4\right)$ with a range of 18.3 to $23.3^{\circ} \mathrm{C}$ (Data not shown; $p=0.156$ ). The average relative humidity was $47.6 \% \pm 3.8$ with no significant difference between facilities (Data not shown; $p=0.708$ ). Patron membership was highest in community centers (7496 \pm 4327), with hospital associated facilities at $2400 \pm 1053$, traditional gyms at $1350 \pm 724$, and CrossFit at $103 \pm 27$ (Mean $\pm \mathrm{SE}$ ). However, the patronage difference was not statistically significant across facilities sampled (Data not shown; $p=0.22$ ). All facilities provided access to hand sanitizer stations except for 2 CrossFit facilities (50\%) and 1 community center (20\%).

\section{Discussion}

This study examined the prevalence and molecular characteristics of $S$. aureus and MRSA sampled from 288 gym surfaces collected from 16 gyms across four different types of gym facilities in Northeast Ohio. From 288 samples, 110 were positive $S$. aureus isolates and we had a $26.7 \%(77 / 288)$ and $11.5 \%(33 / 288)$ recovery of $S$. aureus and MRSA, respectively. We found similar $S$. aureus prevalence across community, traditional, CrossFit, and hospital-associated fitness facilities $(40.0 \%$ vs $38.9 \%$ vs $38.9 \%$ vs $33.3 \%$, respectively) (Table 1 ). However, our prevalence rates were higher than those identified previously [15-21]. The prevalence rate difference may be attributed to fitness facility and/or patron type. As athletes and athletic personnel generally have a significantly higher incidence of both infections and over a ten-fold higher number of antibiotic prescriptions per year compared to the general public, many infections may remain unmonitored or unrecognized [18, 33, 34]. Despite their continual occurrence, there has been little effort to identify and monitor contaminated surfaces and the role they may play in transmission, until recently [35-39]. Though our study found similar rates of contamination across all fitness facilities that mirror common human carriage rates, the incidence of both $S$. aureus and MRSA is higher in our environmental contamination study than what has been observed in the literature, such as in school settings, playgrounds, and beaches [4-8, 15, 22, 40]. Despite other environmental 


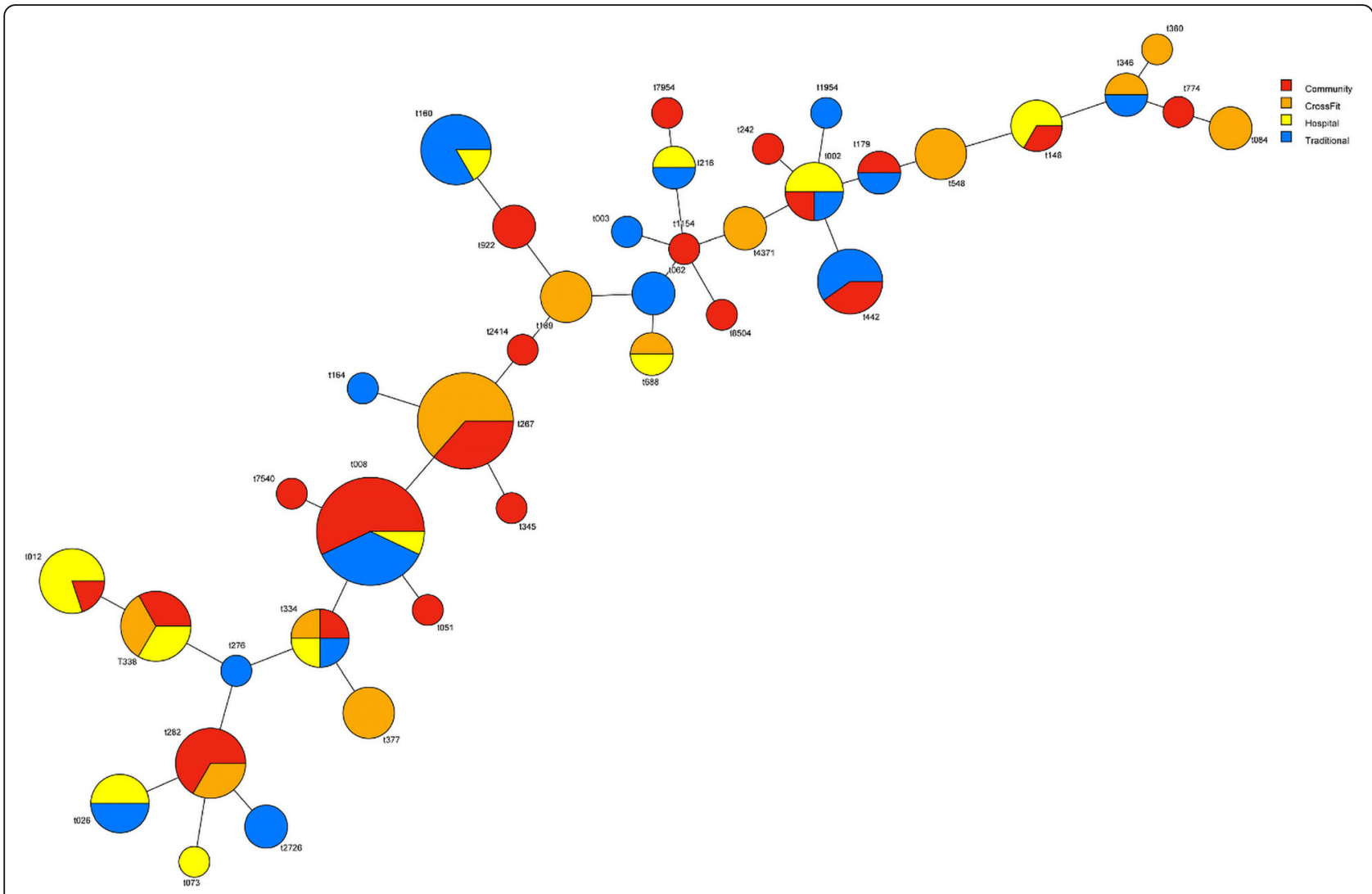

Fig. 2 BURP clustering of spa typing from S. aureus isolates. Color represents fitness facility type with percent of circle equal to percent total of spa type in relation to total positive $S$. aureus isolates identified

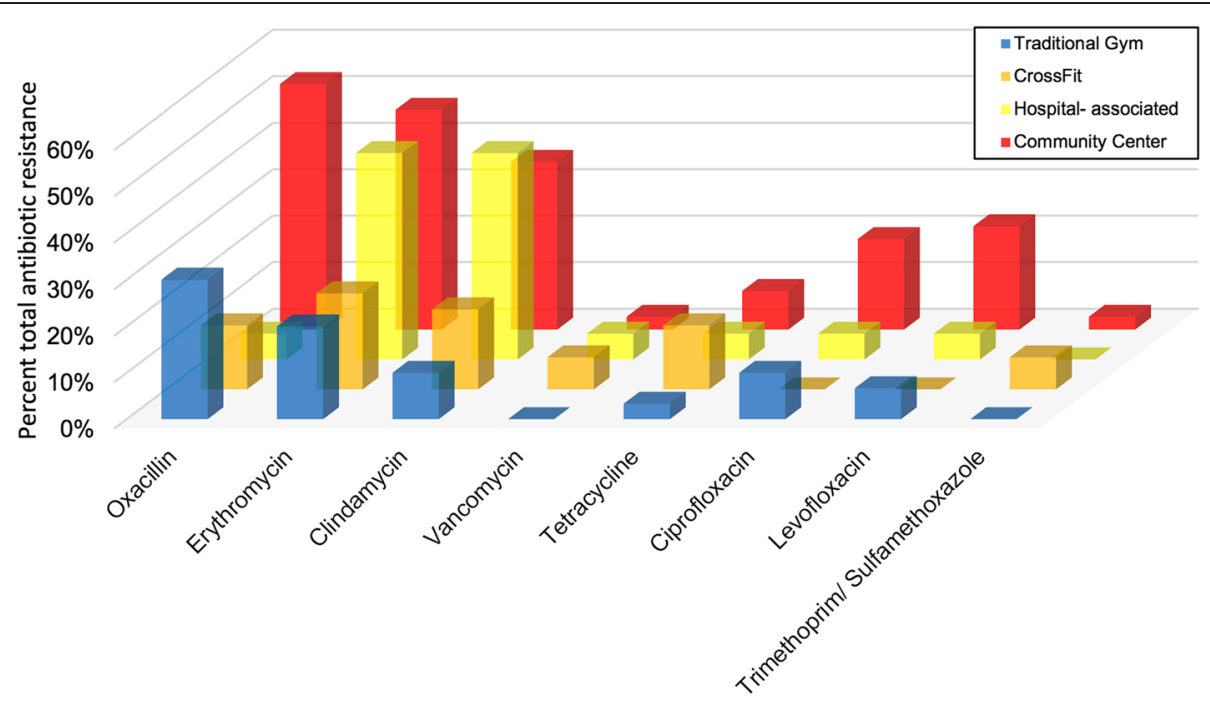

Fig. 3 Percent total antibiotic resistance of positive S. aureus isolates by fitness facility location. *All vancomycin resistance is intermediate 
contamination studies, studies of fitness facilities have received attention only recently.

For example, Ryan and colleagues [22] found zero presence of $S$. aureus in gym facility surfaces suggesting that all transmission was entirely via-person to person contact or at least ruling out that gyms were reservoirs of S. aureus. Markley and colleagues [15] sampled 16 different surface types at one large community center and found that $10 \%(10 / 99)$ of samples were contaminated with MSSA only. Due to the significantly limited size and scope of the study (one facility type was examined), their reported incidence may be underestimated. Prior to these studies, 5 players (9\%) on the 2003 St. Louis Rams football team were found to have MRSA infections [18]. Interestingly, they found zero nasal carriers and/or environmental reservoirs of MRSA, but did grow MSSA from whirlpool water and a gel-applicator stick used for taping ankles, suggesting that fomite surfaces have the potential to harbor and transmit $S$. aureus. Although Ryan and colleagues [22] surveyed three facilities (college, high school, and private gyms) before and after cleaning regiments, they found zero presence of MSSA and MRSA from their 240 samples. Their results may be attributed to differences in bacterial isolation and cultivation. Almost $40 \%$ of the population are carriers of $S$. aureus [41], thus, it is surprising that these studies found very few contaminated surfaces, while contamination in a hospital setting is sufficiently ubiquitous to sound alarm [42-46]. For example, a hospital study found that $76 \%$ of skin and soft tissue infections were of S. aureus etiology and 59\% of those were attributable to MRSA [47]. Of those presenting MRSA, 99\% of isolates were community-associated (CA-MRSA), pointing to acquisition of MRSA strains from outside of the hospital setting, such as a gym facility. Likewise, hospital ward high touch surfaces areas were highly contaminated with $S$. aureus concentration increasing by almost $80 \%$ over a 4 -h period despite the use of hypochlorite. The addition of Quaternary Ammonium Compound surfactants (QAC) did drastically decontaminate surfaces to almost $10 \%$ of their original bacterial load count, pointing to potential bacterial decontamination strategies to reduce transmission [46]. Additionally, through the use of sequencing techniques, small amounts of biomass collected from gym facilities were sufficient to identify community bacteria, as well as staphylococcal species present on athletic surfaces in the gym, with the composition modulated by interacting with human skin [48]. Though our study did not track personnel or patron S. aureus carriage or microbiome composition, provenance of contamination will be key for future studies addressing the movement, transmission, and potential antibiotic-resistant reservoirs of fitness facilities.

The increased prevalence of $S$. aureus on fitness facility surfaces may also be a result of environmental co-evolution. As $S$. aureus can tolerate high osmolarity stress (high saline environments), the production of sweat at gym facilities can even be extrapolated to other high intensity situations such as war and combat, which may select for Staphylococcal species in the environment or individual [49]. With ease of horizontal gene transfer, the acquisition of antibiotic resistance may be enhanced as a result. The incidence of MRSA in athletes is almost triple what is observed in the general population. Thus, it is not surprising that we observed higher contamination rates on gym surfaces than other surfaces [50].

We found a total of 38 unique spa types with t008 (14; 12.7\%) and t267 (11; 10.0\%) being the most common (Table 2; Fig. 2). Interestingly, some loosely identified livestock associated strains such as t548 and t338 were found in Crossfit, community, and hospital-associated strains but not in strains isolated from traditional gyms (Fig. 2). t548 is associated to upper Midwestern and northwestern regions of the US, including Ohio. Since it was found in hospital associated gyms, the line between the original provenance of $S$. aureus strains and their site of contamination is becoming increasingly fluid. Approximately $8.2 \%(9 / 110)$ of strains were categorized as livestock-associated. A total of 6 isolates were t338 and were found in hospital, Crossfit, and community fitness facilities. Three isolates (2.7\%) were t548 and found solely within Crossfit facilities. Additionally, t012 was the most common strain type found in hospital-associated facilities $(4 ; 22.0 \%)$ and community fitness centers $(1 ; 3.0 \%)$, but not traditional or Crossfit facilities. t012 is known to be less prevalent as the age of the individual increases [51, 52]. However, its increased incidence in hospital- associated facilities may be a result of rehabilitation of both older and younger patients. Conversely, t002 was found in hospital-associated $(2 ; 11.0 \%)$, community $(1 ; 3.0 \%)$, and traditional facilities $(1 ; 4.0 \%)$. t002 is often found in nursing homes and in older patients [53]. As such, the hospital-associated facilities also had strains associated with older patients. These results suggest that age demographics may play a significant role in strain isolates found in various fitness facilities. We found $t 002$ on the weight ball and weight bench bars in hospital, traditional, and community facilities. As it has the possibility to be present in cases of bacteremia [52, 54], it is important to be careful in regards to lifting weights with any cuts present, which could contaminate gym equipment.

Looking across gym facilities, Crossfit had the most diverse range of spa types (Table 2; Fig. 2). Of the 10 spa types found in Crossfit facilities, 6 were community-associated (t267, t377, t084, t282, t334, and t4371), two have been found in livestock (t548 and t338), and two have been associated in hospital settings (t189 and t346). Though other facilities sampled had some similar variations of these associations, none were as diverse as Crossfit 
types. This may be a result of the comparative lack of lifting machine structure in Crossfit gyms and/ or the wide range of people that attend them $[55,56]$. Furthermore, if common cleaning regimens are not followed, high hand-touch surfaces may harbor and easily disseminate pathogenic, antibiotic resistant bacteria to other people via hand contact, as hands are recognized as a primary mode of transmission of many diseases (Fig. 3), [38, 45, 57].

To the best of our knowledge, this is the first study to evaluate systematically different gym facility types for contamination and molecular typing of $S$. aureus. The strength of our study resides within our large sample size both across fitness facility types, as well as across fitness surfaces sampled. In addition, we also carried out molecular genotyping of $S$. aureus isolates, further strengthening our epidemiological study of $S$. aureus contamination on athletic gym surfaces. However, there are limitations to our study that included convenience sampling in Northeast Ohio fitness facilities only. In addition, we only sampled surfaces at one point in time, we did not sample surfaces after a cleaning regimen, and we did not sample and type isolates found on patrons and facility employees. Future studies should evaluate the patron microbiome, as well as the collective microbiota impact on fomite contamination and transmission. Our results indicate not only the presence of putatively dangerous isolates of $S$. aureus, but also that increased cleaning regimens and enhanced hygiene practices should be followed in fitness facilities as is practiced in the hospital or work place.

\section{Conclusions}

Of 288 surfaces swabbed from 16 different facilities (traditional gyms, community centers, hospital-associated facilities, and CrossFit facilities), 38.2\% (110/288) of surfaces were positive for S. aureus. $30.0 \%$ of all isolates were mecA-positive with community-associated fitness facilities containing the most mecA (17.3\%) compared to traditional, CrossFit, and hospital-associated fitness centers (8.20, 3.64 and $0.91 \%$, respectively). t008 was the most common spa type present across all gym facility types. All fitness locations were contaminated with both $S$. aureus and MRSA, and $36.4 \%$ of all positive isolates were multidrug-resistant.

\footnotetext{
Abbreviations

AST: antibiotic susceptibility testing; BURP: Based upon Repeat Pattern; CAMRSA: community-associated Methicillin resistant Staphylococcus aureus; HVAC: Heating, ventilation, and air conditioning; MDR: multi-drug resistant; MLST: Multilocus sequence typing; MRSA: Methicillin resistant Staphylococcus aureus; MSSA: methicillin-susceptible S. aureus; PVL: Panton-Valentine leukocidinPCRPolymerase chain reaction; QAC: Quaternary Ammonium Compound surfactants
}

Acknowledgements

We would like to thank Kent State University and CRDF Global initiative.

\section{Funding}

This research was supported financially by startup funds to TCS and in part by CRDF Global research funds to TCS/ HMN. The funders had no role in the design of the study and collection, analysis, or interpretation of data or in writing the manuscript.

\section{Availability of data and materials}

All relevant materials and data supporting the findings of this study are contained within the manuscript. Raw data can be requested from the corresponding author.

\section{Authors' contributions}

MD was involved in all aspects of research design, implementation, and writing the manuscript. SB, NN, HO, DT, and HMN were involved in sample acquisition and/or molecular work. TCS was involved in manuscript revision and overall study design. All authors were involved in drafting and approving the final manuscript, and give final approval for the manuscript.

Ethics approval and consent to participate

Not applicable. However, access to facilities was through written consent by owner.

\section{Consent for publication}

Not applicable.

\section{Competing interests}

The authors declare that they have no competing interests.

\section{Publisher's Note}

Springer Nature remains neutral with regard to jurisdictional claims in published maps and institutional affiliations.

\section{Author details}

${ }^{1}$ Kent State University, College of Podiatric Medicine, 6000 Rockside Woods Blvd. N, Independence, OH 44131, USA. ²Department of Biostatistics, Environmental Health Sciences and Epidemiology, Kent State University, College of Public Health, Kent, OH, USA. ${ }^{3}$ Department of Microbiology, Kabul University, Faculty of Pharmacy, Jamal Meena street, Kabul, Afghanistan.

Received: 10 September 2018 Accepted: 9 January 2019

Published online: 18 January 2019

\section{References}

1. Graham PL, Lin SX, Larson EL. A US population-based survey of Staphylococcus aureus colonization. Ann Intern Med. 2006;144:318-25.

2. Gorwitz RJ, Kruszon-Moran D, McAllister SK, McQuillan G, McDougal LK, Fosheim GE, Jensen BJ, Killgore G, Tenover FC, Kuehnert MJ. Changes in the prevalence of nasal colonization with Staphylococcus aureus in the United States, 2001-2004. J Infect Dis. 2008;197:1226-34.

3. Dantes R, Mu Y, Belflower R, Aragon D, Dumyati G, Harrison LH, Lessa FC, Lynfield R, Nadle J, Petit S, et al. National burden of invasive methicillinresistant Staphylococcus aureus infections, United States, 2011. JAMA Intern Med. 2013;173:1970-8.

4. Thapaliya D, Dalman M, Kadariya J, Little K, Mansell V, Taha M, Grenier D, Smith T. Characterization of Staphylococcus aureus in goose feces from state Parks in Northeast Ohio. EcoHealth. 2017;14(2):303-9.

5. Thapaliya D, Forshey BM, Kadariya J, Quick MK, Farina S, O'Brien A, Nair R, Nworie A, Hanson B, Kates A. Prevalence and molecular characterization of Staphylococcus aureus in commercially available meat over a one-year period in lowa, USA. Food Microbiol. 2017;65:122-9.

6. Thapaliya D, Hellwig EJ, Kadariya J, Grenier D, Jefferson AJ, Dalman M, Kennedy K, DiPerna M, Orihill A, Taha M. Prevalence and characterization of Staphylococcus aureus and methicillin-resistant Staphylococcus aureus on public recreational beaches in Northeast Ohio. GeoHealth. 2017;1:320-32.

7. Thapaliya D, Taha M, Dalman MR, Kadariya J, Smith TC. Environmental contamination with Staphylococcus aureus at a large, Midwestern university campus. The Sci Total Environ. 2017;599:1363-8.

8. Thapaliya D, Kadariya J, Capuano M, Rush H, Yee C, Oet M, Lohani S, Smith TC. Prevalence and Molecular Characterization of S. aureus and MRSA on Children's Playgrounds. Pediatr Infect Dis J. 2018. https://doi.org/10.1097/ INF.0000000000002095. 
9. Carrel M, Zhao C, Thapaliya D, Bitterman P, Kates AE, Hanson BM, Smith TC. Assessing the potential for raw meat to influence human colonization with Staphylococcus aureus. Sci Rep. 2017;7:10848.

10. Kates A, Dalman M, Torner J, Smith T. A Cross-Sectional Study Of Staphylococcus aureus Colonization And The Nasal And Oropharyngeal Microbiomes. BioRxiv. 2017. 145540. https://doi.org/10.1101/145540.

11. Kates AE, Thapaliya D, Smith TC, Chorazy ML. Prevalence and molecular characterization of Staphylococcus aureus from human stool samples. Antimicrob Resist Infect Control. 2018;7:42.

12. Ramos N, Stachel A, Phillips M, Vigdorchik J, Slover J, Bosco JA. Prior Staphylococcus aureus nasal colonization: a risk factor for surgical site infections following decolonization. J Am Acad Orthop Surg. 2016;24:880-5.

13. Knox J, Sullivan SB, Urena J, Miller M, Vavagiakis P, Shi Q, Uhlemann A-C, Lowy FD. Association of environmental contamination in the home with the risk for recurrent community-associated, methicillin-resistant Staphylococcus aureus infection. JAMA Intern Med. 2016;176:807-15.

14. Club Business International: The IHRSA Global report 2011. https://www. globalwellnesssummit.com/wp-content/uploads/Industry-Research/Global/ 2012-ihrsa-global-report.pdf. Accessed 10 Dec 2018.

15. Markley JD, Edmond MB, Major Y, Bearman G, Stevens MP. Are gym surfaces reservoirs for Staphylococcus aureus? A point prevalence survey. Am J Infect Control. 2012;40:1008-9.

16. Scott E, Duty S, Callahan M. A pilot study to isolate Staphylococcus aureus and methicillin-resistant $S$ aureus from environmental surfaces in the home. Am J Infect Control. 2008;36:458-60.

17. Begier EM, Frenette K, Barrett NL, Mshar P, Petit S, Boxrud DJ, WatkinsColwell K, Wheeler S, Cebelinski EA, Glennen A. A high-morbidity outbreak of methicillin-resistant Staphylococcus aureus among players on a college football team, facilitated by cosmetic body shaving and turf burns. Clin Infect Dis. 2004:39:1446-53.

18. Kazakova SV, Hageman JC, Matava M, Srinivasan A, Phelan L, Garfinkel B, Boo T, McAllister S, Anderson J, Jensen B, et al. A clone of methicillinresistant Staphylococcus aureus among professional football players. N Engl J Med. 2005;352:468-75.

19. Romano R, Lu D, Holtom P. Outbreak of community-acquired methicillinresistant Staphylococcus aureus skin infections among a collegiate football team. J Athl Train. 2006;41:141-5.

20. Rihn JA, Michaels MG, Harner CD. Community-acquired methicillin-resistant Staphylococcus aureus: an emerging problem in the athletic population. Am J Sports Med. 2005:33:1924-9.

21. Borchardt SM. Outbreak of methicillin-resistant Staphylococcus aureus skin infections among high school athletes in Illinois. III Infect Dis Rep. 2005;2(3):1-3.

22. Ryan KA, Ifantides C, Bucciarelli C, Saliba H, Tuli S, Black E, Thompson LA. Are gymnasium equipment surfaces a source of staphylococcal infections in the community? Am J Infect Control. 2011;39:148-50.

23. Moritz ED, Hanson BM, Kates AE, Smith TC. Molecular characteristics of Staphylococcus aureus isolated from employees, children, and environmental surfaces in lowa child daycare facilities. Am J Infect Control. 2015:43:482-8.

24. Lina G, Boutite F, Tristan A, Bes M, Etienne J, Vandenesch F. Bacterial competition for human nasal cavity colonization: role of staphylococcal agr alleles. Appl Environ Microbiol. 2003;69:18-23.

25. Boşgelmez-Tinaz G, Ulusoy S, Aridoğan B, Coşkun-Ari F. Evaluation of different methods to detect oxacillin resistance in Staphylococcus aureus and their clinical laboratory utility. Eur J Clin Microbiol Infect Dis. 2006;25:410-2.

26. Shopsin B, Gomez M, Montgomery SO, Smith DH, Waddington M, Dodge DE, Bost DA, Riehman M, Naidich S, Kreiswirth BN. Evaluation of protein a gene polymorphic region DNA sequencing for typing of Staphylococcus aureus strains. J Clin Microbiol. 1999;37:3556-63.

27. Koreen L, Ramaswamy SV, Graviss EA, Naidich S, Musser JM, Kreiswirth BN. spa typing method for discriminating among Staphylococcus aureus isolates: implications for use of a single marker to detect genetic micro- and macrovariation. J Clin Microbiol. 2004;42:792-9.

28. O'Hara FP, Suaya JA, Ray GT, Baxter R, Brown ML, Mera RM, Close NM, Thomas E, Amrine-Madsen H. spa typing and multilocus sequence typing show comparable performance in a macroepidemiologic study of Staphylococcus aureus in the United States. Microb Drug Resist. 2016;22:88-96.

29. Mellmann A, Weniger T, Berssenbrügge C, Keckevoet U, Friedrich AW, Harmsen D, Grundmann H. Characterization of clonal relatedness among the natural population of Staphylococcus aureus strains by using spa sequence typing and the BURP (based upon repeat patterns) algorithm. J Clin Microbiol. 2008:46:2805-8.

30. Faria NA, Carrico JA, Oliveira DC, Ramirez M, de Lencastre H. Analysis of typing methods for epidemiological surveillance of both methicillinresistant and methicillin-susceptible Staphylococcus aureus strains. J Clin Microbiol. 2008;46:136-44.

31. Sangvik M. Staphylococcus aureus Colonisation and Host-Microbe Interactions [PhD thesis]. Tromsø: University of Tromsø UIT; 2013.

32. Magiorakos A-P, Srinivasan A, Carey RB, Carmeli Y, Falagas ME, Giske CG, Harbarth S, Hindler JF, Kahlmeter G, Olsson-Liljequist B, et al. Multidrugresistant, extensively drug-resistant and pandrug-resistant bacteria: an international expert proposal for interim standard definitions for acquired resistance. Clin Microbiol Infect. 2012;18:268-81.

33. Friman G, Wesslén L. Special feature for the Olympics: effects of exercise on the immune system: infections and exercise in high-performance athletes. Immunol Cell Biol. 2000;78:510-22.

34. Halem M, Trent J, Green J, Kerdel F. Community-acquired methicillin resistant Staphylococcus aureus skin infection. Semin Cutan Med Surg. 2006;25:68-71.

35. Cohen PR. Community-acquired methicillin-resistant Staphylococcus aureus skin infections: implications for patients and practitioners. Am J Clin Dermatol. 2007:8:259-70

36. Mitchell JJ, Jackson JM, Anwar A, Singleton SB. Bacterial sport-related skin and soft-tissue infections (SSTIs): an ongoing problem among a diverse range of athletes. JBJS Rev. 2017;5. https://doi.org/10.2106/JBJS.RWW.16.00006.

37. Lin MY, Hayden MK, Lyles RD, Lolans K, Fogg LF, Kallen AJ, Weber SG, Weinstein RA, Trick WE. Regional epidemiology of methicillin-resistant Staphylococcus aureus among adult intensive care unit patients following state-mandated active surveillance. Clin Infect Dis. 2018;66:1535-9.

38. Desai R, Pannaraj PS, Agopian J, Sugar CA, Liu GY, Miller LG. Survival and transmission of community-associated methicillin-resistant Staphylococcus aureus from fomites. Am J Infect Control. 2011;39:219-25.

39. Haghverdian BA, Patel N, Wang L, Cotter JA. The sports ball as a fomite for transmission of Staphylococcus aureus. J Environ Health. 2018;80(6):8-13.

40. Smith TC, Moritz ED, Larson KRL, Ferguson DD. The environment as a factor in methicillin-resistant Staphylococcus aureus transmission. Rev Environ Health. 2011;25:121-34.

41. Kluytmans J, van Belkum A, Verbrugh H. Nasal carriage of Staphylococcus aureus: epidemiology, underlying mechanisms, and associated risks. Clin Microbiol Rev. 1997;10:505-20.

42. Wagenvoort JHT, Sluijsmans W, Penders RJR. Better environmental survival of outbreak vs. sporadic MRSA isolates. J Hosp Infect. 2000;45:231-4.

43. French GL, Otter JA, Shannon KP, Adams NMT, Watling D, Parks MJ. Tackling contamination of the hospital environment by methicillin-resistant Staphylococcus aureus (MRSA): a comparison between conventional terminal cleaning and hydrogen peroxide vapour decontamination. J Hosp Infect. 2004:57:31-7.

44. Bartels MD, Kristoffersen $K$, Slotsbjerg T, Rohde SM, Lundgren B, Westh $H$. Environmental meticillin-resistant Staphylococcus aureus (MRSA) disinfection using dry-mist-generated hydrogen peroxide. J Hosp Infect. 2008;70:35-41.

45. Dancer SJ. Importance of the environment in meticillin-resistant Staphylococcus aureus acquisition: the case for hospital cleaning. Lancet Infect Dis. 2008;8:101-13.

46. Yuen JWM, Chung TWK, Loke AY. Methicillin-resistant Staphylococcus aureus (MRSA) contamination in bedside surfaces of a hospital ward and the potential effectiveness of enhanced disinfection with an antimicrobial polymer surfactant. Int J Environ Res Public Health. 2015;12:3026-41.

47. Kirkland EB, Adams BB. Methicillin-resistant Staphylococcus aureus and athletes. J Am Acad Dermatol. 2008:59:494-502.

48. Wood M, Gibbons SM, Lax S, Eshoo-Anton TW, Owens SM, Kennedy S, Gilbert JA, Hampton-Marcell JT. Athletic equipment microbiota are shaped by interactions with human skin. Microbiome. 2015;3:25.

49. Calhoun JH, Murray CK, Manring MM. Multidrug-resistant organisms in military wounds from Iraq and Afghanistan. Clin Orthop Relat Res. 2008;466:1356-62.

50. Oller AR, Province L, Curless B. Staphylococcus aureus recovery from environmental and human locations in 2 collegiate athletic teams. J Athl Train. 2010;45:222-9.

51. Nulens E, Broex E, Ament A, Deurenberg RH, Smeets E, Scheres J, van Tiel FH, Gordts B, Stobberingh EE. Cost of the meticillin-resistant Staphylococcus aureus search and destroy policy in a Dutch university hospital. J Hosp Infect. 2008;68:301-7. 
52. Hetem DJ, Bootsma MCJ, Troelstra A, Bonten MJM. Transmissibility of livestock-associated methicillin-resistant Staphylococcus aureus. Emerg Infect Dis. 2013;19:1797-802.

53. Stark L, Olofsson M, Lofgren S, Molstad S, Lindgren P-E, Matussek A. Prevalence and molecular epidemiology of Staphylococcus aureus in Swedish nursing homes- as reveled in SHADES study. Epidemiol Infect. 2014;142(6):1310-6.

54. Hasman H, Moodley A, Guardabassi L, Stegger M, Skov RL, Aarestrup FM. Spa type distribution in Staphylococcus aureus originating from pigs, cattle and poultry. Vet Microbiol. 2010;141:326-31.

55. Gerhart HD. A comparison of crossfit training to traditional anaerobic resistance training in terms of selected fitness domains representative of overall athletic performance. Master. Indiana: Indiana University of Pennsylvania, Health and Physical Education; 2013. Report No. 1175

56. Meyer J, Morrison J, Zuniga J. The benefits and risks of CrossFit: a systematic review. Workplace Health Saf. 2017;65:612-8.

57. Miller LG, Eells SJ, David MZ, Ortiz N, Taylor AR, Kumar N, Cruz D, BoyleVavra S, Daum RS. Staphylococcus aureus skin infection recurrences among household members: an examination of host, behavioral, and pathogenlevel predictors. Clin Infect Dis. 2015;60:753-63.

Ready to submit your research? Choose BMC and benefit from:

- fast, convenient online submission

- thorough peer review by experienced researchers in your field

- rapid publication on acceptance

- support for research data, including large and complex data types

- gold Open Access which fosters wider collaboration and increased citations

- maximum visibility for your research: over $100 \mathrm{M}$ website views per year

At $\mathrm{BMC}$, research is always in progress.

Learn more biomedcentral.com/submissions 